\title{
Effect of Acid Etching Time and Concentration on Oxygen Content of Powder on the Microstructure and Elastic Properties of Silicon Carbide Densified by SPS
}

\author{
Zeynep Ayguzer Yasar $^{1}$, Richard Haber ${ }^{2}$ \\ ${ }^{1}$ Design, Osmancık Omerderindere Vocational School, Hitit University, Corum, Turkey \\ ${ }^{2}$ Department of Material Science and Engineering, Rutgers, The State University of New Jersey, Piscataway, USA
}

Email address:

rich.haber@rutgers.edu (R. Haber)

\section{To cite this article:}

Zeynep Ayguzer Yasar, Richard Haber. Effect of Acid Etching Time and Concentration on Oxygen Content of Powder on the Microstructure and Elastic Properties of Silicon Carbide Densified by SPS. International Journal of Materials Science and Applications.

Vol. 9, No. 1, 2020, pp. 7-13. doi: 10.11648/j.ijmsa.20200901.12

Received: January 27, 2020; Accepted: February 12, 2020; Published: February 28, 2020

\begin{abstract}
In this current paper, oxygen content of a fine particle size SiC (H. C. Starck UF 25 Silicon Carbide) and coarser particle size SiC (Saint Gobain Silicon Carbide) were modified by using different concentrations of HF for etching. Fully dense silicon carbide ceramics ( $>99 \%$ th. density) were produced by the spark plasma sintering technique at $1950{ }^{\circ} \mathrm{C}$ under an applied pressure of $50 \mathrm{MPa}$ for $5 \mathrm{~min}$ hold with boron carbide and carbon addition. Archimedes method, scanning electron microscopy, and the ultrasound analysis were used to examined density, microstructure, elastic (E), shear $(\mathrm{G})$, and bulk (K) moduli of dense silicon carbide ceramics to investigate the effect of oxygen impurities on the densification and the properties of silicon carbide. The results showed that high oxygen content is detrimental to the final density of SPS silicon carbide. When the oxygen content increased from 0.60 to $5.92 \mathrm{wt} . \%$, the relative density decreased from $99.99 \%$ to $96 \%$. For both $\mathrm{SiC}$ powders, by increasing the etching time, the grain size of $\mathrm{SiC}$ decreased. It means that the high oxygen caused grain growth. Ultrasound analysis results showed that the high oxygen content affected the elastic properties. SiC samples with the high oxygen content had a lower elastic moduli, shear moduli and bulk moduli. It was clear that increasing the oxygen content decreased the elastic properties.
\end{abstract}

Keywords: Silicon Carbide, Spark Plasma Sintering, Microstructure

\section{Introduction}

Silicon carbide $(\mathrm{SiC})$ has some outstanding physical and chemical properties, such as low theoretical density (3.21 $\mathrm{g} / \mathrm{cm}^{3}$ ), a high hardness, a high elastic modulus, high thermal conductivity, good wear and oxidation resistance, and low coefficient of thermal expansion [1-8]. Due to those properties, dense silicon carbide is suitable to use in high temperature, corrosion resistant applications and aerospace applications, automotive, wear components and armor [3-4, 9-10]. However, it is difficult to obtain a sintered body with high density without applied pressure or sintering aids, due to high covalent bonds between silicon and carbon atoms and low self diffusion coefficient [1, 10-11].

The other issue with the non-oxide high temperature ceramics such as $\mathrm{SiC}, \mathrm{B}_{4} \mathrm{C}$ and $\mathrm{TiB}_{2}$ is that they tend to have an oxide layer on their surfaces. It depends on particle size, moisture in the air, and additives. This oxide layer causes large grain coarsening and inhibits densification [12-15 ].

There are a number of methods to sinter $\mathrm{SiC}$, for instance, pressureless sintering, hot pressing (HP), spark plasma sintering (SPS) with solid state or liquid phase sintering [10, 16]. In liquid phase sintering of silicon carbide, $\mathrm{Al}_{2} \mathrm{O}_{3}, \mathrm{Y}_{2} \mathrm{O}_{3}$, and other rare earth oxides are commonly used as additivies to form liquid phase $[17,18]$. When using oxide sintering aids in liquid phase sintering, the silica layer $\left(\mathrm{SiO}_{2}\right)$ on the $\mathrm{SiC}$ particles reacts with the other oxides to help form of the liquid phase. Since the Gibbs free energy of $\mathrm{SiO}_{2}$ is strongly negative, the oxygen layer is on the $\mathrm{SiC}$ particle and the oxide layer will inhibit the densification $[1,17]$.

In solid state sintering of silicon carbide, boron containing species and carbon are used as sintering aids. Boron base 
additives increase the rate of self-diffusion coefficients of $\mathrm{Si}$ and $\mathrm{C}$. Carbon removes the $\mathrm{SiO}_{2}$ layer on the silicon carbide surface and also inhibits the grain growth by forming inclusions [19-23].

Magmami et. al. sintered $\mathrm{SiC}$ with boton carbide and carbon addition at $1980^{\circ} \mathrm{C}$ for 7 hours with pressureless sintering, and density reached to $98.4 \%$ [24].

Sajgalık et. al. produced $>99 \%$ dense additive free $\mathrm{SiC}$ with the hot press technique at $1850^{\circ} \mathrm{C}$ for 1 hour holding time under $30 \mathrm{MPa}$ pressure [11].

SPS is a novel method that can produce dense silicon carbide a within short time with high heating rate and pressure. Due to the shorter holding times it can inhibit large grain growth [1-2, 10, 25-26].

Hayun et. al. densified $\mathrm{SiC}$ without additive at $2050^{\circ} \mathrm{C}$ for 10 min with an applied pressure of $69 \mathrm{MPa}$ via SPS. $99 \%$ of theoretical was achieved with this method [27].

Guillard et. al. have also reported that $\mathrm{SiC}$ was densified only $92 \%$ at $1850^{\circ} \mathrm{C}$ with a 5 min holding time under $75 \mathrm{MPa}$ pressure by SPS method without additives [26].

Thus far, researchers have investigated different methods to produce fully dense silicon carbide. However, the effect of oxygen content of silicon carbide on propertiesof dense ceramic has not been addressed as necessary.

The aim of this work was to address the influence of the acid etching process on oxygen content of starting powders on the microstructure and elastic properties of dense silicon carbide. To achieve this goal, two different silicon carbide powders' acids were etched using varying HF concentration, etching time, and neutralizing media and the change in oxygen contents were observed. The spark plasma technique was used to densify silicon carbide powders with boron carbide and carbon additives.

\section{Experimental}

Four different raw materials were used for this research including H. C. Starck silicon carbide (UF-25, H. C. Starck GmbH\&Co., Germany), Saint Gobain silicon carbide (Niagara Falls, New York), HC. Starck boron carbide (HD20, H. C. Starck GmbH\&Co., Germany), and carbon (Lamp black from Fisher Scientific) as starting materials. The Saint Gobain powder was not commercially available; it was obtained directly from the Saint Gobain, Niagara Falls, New York plant. The main differences between these two powders were their particle sizes and oxygen contents. The Saint Gobain (SG) powder had larger average particle size of 1.5 $\mu \mathrm{m}$. H. C. Starck (HC) had a smaller average particle size of $0.5 \mu \mathrm{m}$. In the content, $\mathrm{HC}-\mathrm{SiC}$ will refer fine $\mathrm{SiC}$, and SG$\mathrm{SiC}$ will refer coarse SiC. A LECO TC600 oxygen/nitrogen analyzer was used to determine the oxygen content of silicon carbides. To reduce oxygen content of powders both powders were acid etched.

To modify the oxygen content of powder fine silicon carbide was etched with $20 \%, 40 \%, 50 \% \mathrm{HF}$, and HF\&NHO3 acid for 1, 4, and 24 hours. The acidic slurry was neutralized with ethanol and ammonium hydroxide.
Table 1. Acid etching conditions.

\begin{tabular}{llll}
\hline Acid & $\begin{array}{l}\text { Concentration } \\
(\%)\end{array}$ & $\begin{array}{l}\text { Etching Time } \\
\text { (Hour) }\end{array}$ & Neutralized with \\
\hline $\mathrm{HF}$ & 20 & 24 & Ethanol \\
$\mathrm{HF}$ & 40 & $1-4-24$ & Ammonium Hydroxide \\
$\mathrm{HF}$ & 50 & $1-4-24$ & Ammonium Hydroxide \\
$\mathrm{HF} \& \mathrm{HNO}_{3}$ & $40-65$ & $1-4-24$ & Ammonium Hydroxide \\
\hline
\end{tabular}

$60 \mathrm{~g}$ SiC powder was mixed with $200 \mathrm{ml}$ different concentrations of HF (Acros Organics) and stirred for 1, 4, or 24 hours in a Nalgene HDPE beaker, and neutralized until it reached $\mathrm{pH} 7$, then centrifuged to separate the liquid from the silicon carbide powder. Afterwards, wet silicon carbide was washed with deionized water three times and silicon carbide powder dried in a drying oven. Using a mortar and pestle the dry powder cake was ground to fine powder.

As a result of these experiments, 1 hour etching with 50\% $\mathrm{HF}$ and neutralization with ammonium hydroxide was chosen. Coarse SiC powder was etched only with this method.

The matrix of samples consist of $\mathrm{B}_{4} \mathrm{C}, \mathrm{C}$, and SiC. 0.5 wt. $\% \mathrm{~B}_{4} \mathrm{C}, 1.5$ wt. $\% \mathrm{C}$, and $\mathrm{SiC}$ were weighed and put in a Nalgene bottle with $\mathrm{SiC}$ ball and ball milled for 24 hours in ethanol. After milling, the mixture was sieved to separate media from the liquid mixture using a mesh sieve $(1.4 \mathrm{~mm})$, dried on a hot plate at $275^{\circ} \mathrm{C}$, and ground to uniformity with mortar and pestle.

All samples were then sintered by Spark plasma sintering (Thermal Technology). 5 grams of each powder mixture was loaded into a graphite die (20 mm inner diameter) with graphite punches. The inside of the graphite die was lined with graphite foil. Samples were sintered using a two stage sintering. SPS was heated up to $1400^{\circ} \mathrm{C}$ with a $200^{\circ} \mathrm{C} / \mathrm{min}$ heating rate under vacuum with an applied pressure of $50 \mathrm{MPa}$ and it was held at $1400^{\circ} \mathrm{C}$ for 1 minute. After intermediate holding, the samples were heated up to $1950^{\circ} \mathrm{C}$ at $200^{\circ} \mathrm{C} / \mathrm{min}$, under $50 \mathrm{MPa}$ applied pressure and held for 5 min. After that, the SPS was shut down and the samples were allowed to cool.

After sintering, to remove excess graph foil from the surface, the dense samples were sandblasted. Surface grinding was necessary after sand blasting to produce a smooth and flat surface for ultrasound analysis to measure elastic properties. The density was measured using the Archimedes method after surface grinding. Then, samples were cut close to the center of the sample using a LECO Vari/Cut 50 diamond saw. A small piece was chosen and mounted with epoxy using a Buehler SimpliMet 1000 mounting press. Samples were then polished down to 0.25 $\mu \mathrm{m}$ finish using the Buehler- Ecomet 250-Grinder-Polisher. To highlight $\mathrm{SiC}$ grain boundaries, a modified Murakami method $(20 \mathrm{~g} \mathrm{KOH}$ and $20 \mathrm{~g} \mathrm{~K} 3 \mathrm{Fe}(\mathrm{CN}) 6$ in $60 \mathrm{ml}$ DI water) was used to etch (for $4.5 \mathrm{~min}$ ) the pieces of the polished samples. Etched pieces were washed with acetone and ethanol to remove residual salt. The Zeiss Sigma field emission scanning electron microscope was used to define grain size, and shape of grains. Grain sizes were measured by 
the linear intercepts using Lince 2.4.2. image analysis software. The ultrasound analysis method was used to measure the elastic properties.

\section{Results and Discussion}

LECO TC 600 oxygen/nitrogen analyzer was used to measured oxygen content of both SiC powders. Each oxygen content result represents the mean of three analyses. The oxygen content of fine $\mathrm{SiC}$ was $1.69 \pm 0.04 \mathrm{wt} \%$ before the acid etching process. The acid etching conditions and oxygen content of fine $\mathrm{SiC}$ after etching process is shown in Table 2. While increasing the concentration of HF, it also increased the efficiency of acid etching to remove the oxide layer. The oxygen content of $\mathrm{SiC}$ powder for $20 \% \mathrm{HF}, 40 \% \mathrm{HF}$, and $50 \% \mathrm{HF}$ for 24 -hours etching was $1.09 \pm 0.04 \mathrm{wt} \%, 0.75 \pm 0.03$ $\mathrm{wt} \%$, and $0.48 \pm 0.03 \mathrm{wt} \%$ respectively. When the longer etching time was used, the oxygen content of the etched silicon carbide powder slightly decreased. Nevertheless, increasing the etching time of powder did not decrease the oxygen content as much as expected. The oxygen content of powder for $40 \% \mathrm{HF}$ and $50 \% \mathrm{HF}$ for 1 hour, 4 hours, and 24 hours was $0.82 \pm 0.01 \mathrm{wt} \%, 0.81 \pm 0.01 \mathrm{wt} \%, 0.75 \pm 0.03 \mathrm{wt} \%$, $0.60 \pm 0.02 \mathrm{wt} \%, 0.56 \pm 0.02 \mathrm{wt} \%$, and $0.48 \pm 0.03 \mathrm{wt} \%$, respectively. In the time frame, 1 hour etching was more effective thus $\mathrm{SiC}$ powder etched for 1 hour with $50 \% \mathrm{HF}$ was chosen despite the lower oxygen content in 50\% HF for 4 and 24-hour etching. Etching silicon carbide powder with $75 \% \mathrm{HF} \& 25 \% \mathrm{HNO}_{3}$ did not decrease oxygen content; in contrast, it increased the oxygen content of powder because $\mathrm{HNO}_{3}$ acted as a strong oxidizing agent. The oxygen content of powder for 1 hour, 4 hours and 24 hours was $1.45 \pm 0.02$ wt $\%, 5.07 \pm 0.06 \mathrm{wt} \%$, and $5.92 \pm 0.04 \mathrm{wt} \%$, respectively.

Table 2. Acid etching conditions and oxygen content of fine SiC powder.

\begin{tabular}{lllll}
\hline Acid & $\begin{array}{l}\text { Concentration } \\
(\%)\end{array}$ & $\begin{array}{l}\text { Etching } \\
\text { Time (Hour) }\end{array}$ & $\begin{array}{l}\text { Neutralized } \\
\text { with }\end{array}$ & $\begin{array}{l}\text { Oxygen Content } \\
\text { (wt.\%) }\end{array}$ \\
\hline $\mathrm{HF}$ & 20 & 24 & Ethanol & $1.09 \pm 0.04$ \\
& & 1 & Ammonium & $0.82 \pm 0.01$ \\
$\mathrm{HF}$ & 40 & 4 & Hydroxide & $0.81 \pm 0.01$ \\
& & 24 & & $0.75 \pm 0.03$ \\
& & 1 & Ammonium & $0.60 \pm 0.02$ \\
$\mathrm{HF}$ & 50 & 4 & Hydroxide & $0.56 \pm 0.02$ \\
& & 24 & & $0.48 \pm 0.03$ \\
& & 1 & Ammonium & $1.45 \pm 0.02$ \\
$\mathrm{HF} \&$ & \multirow{2}{*}{$40-65$} & 4 & Hydroxide & $5.07 \pm 0.06$ \\
$\mathrm{HNO}_{3}$ & & 24 & & $5.92 \pm 0.04$ \\
\hline
\end{tabular}

After acid etching, oxygen content of fine SiC powder's dramatically decreased to $0.60 \pm 0.02 \mathrm{wt} \%$ from $1.69 \pm 0.04$ $\mathrm{wt} \%$. When the acid etching process removed the oxide layer from powder, it has also created new surfaces on the powders which tend to oxidize. The oxide layer forms on the surface of freshly etched powders as soon as it is exposed to the air. For that reason, the oxygen content of powders cannot be lowered to $0 \%$.

Coarse $\mathrm{SiC}$ had $0.38 \pm 0.01 \mathrm{wt} \%$ oxygen content before the acid etching treatment. The powder was etched with $50 \% \mathrm{HF}$ for 1 hour, and oxygen content was measured as $0.20 \pm 0.01$ $w t \%$. To determine the lifetime of the powder, acid etched dry powder was allowed to age at ambient conditions. The oxygen growth curve of acid etched coarse $\mathrm{SiC}$ can be seen in Figure 1. The oxygen content of acid etched $\mathrm{SiC}$ powders was measured at different times, and after 14 days oxygen content increased to $0.31 \pm 0.01 \mathrm{wt} \%$ from $0.20 \pm 0.01 \mathrm{wt} \%$.

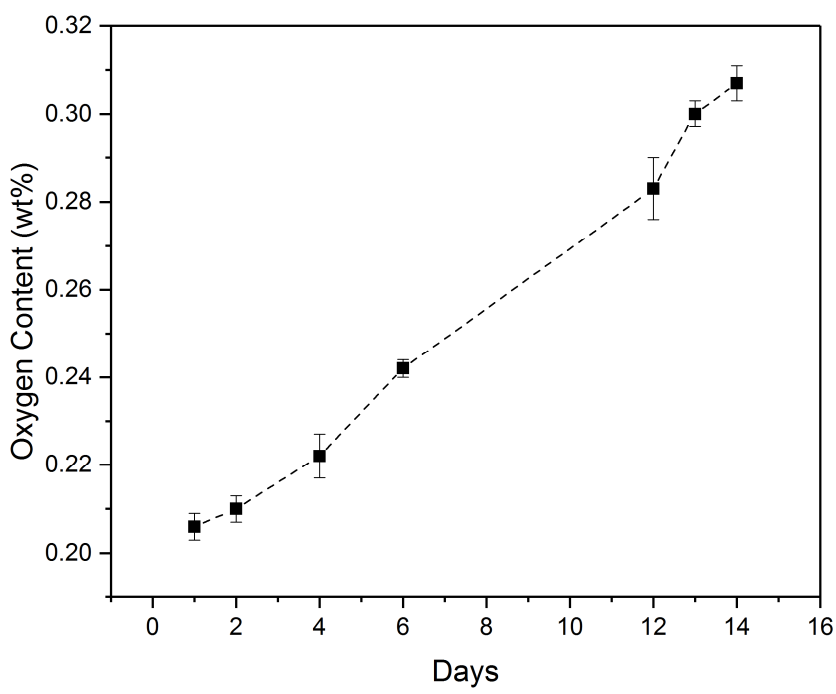

Figure 1. Oxygen growth curve for Saint Gobain SiC.

Fine $\mathrm{SiC}$ (H. C. Starck)

Figure 2 showed microstructure images of $40 \% \mathrm{HF}$, $50 \% \mathrm{HF}$, and $\mathrm{HF}$ and $\mathrm{HNO}_{3}$ etched fine silicon carbide. Density, grain size and elastic properties of dense fine $\mathrm{SiC}$ results can be seen in Table 3. Each value represents the mean of five measurements. SEM images showed that samples made with fine silicon carbide powder had mainly elongated grains. As the etching time increased, the grain size decreased. For $40 \% \mathrm{HF}$ etched samples, the grain size changed from $3.57 \mu \mathrm{m}$ to $2.80 \mu \mathrm{m}$ as the etching time increased. The 1 hour $(3.57 \mu \mathrm{m})$ and 4 hour $(3.02 \mu \mathrm{m}) 40 \%$ HF etched samples showed some exaggerated grain growth with several micron grains, while the 24 hour $(2.80 \mu \mathrm{m}) 40 \%$ HF etched sample shows smaller grains. The $50 \%$ HF etched samples showed little difference in grain size with decreased oxygen content. The 1 hour, 4 hour, and 24 hours samples had a $2.89 \mu \mathrm{m}, 2.71 \mu \mathrm{m}$, and $2.63 \mu \mathrm{m}$ grain size respectively. The $40 \% \mathrm{HF}$ etched samples had bigger grain sizes than the $50 \%$ HF etched samples since the oxygen content of the starting powder was higher. The $\mathrm{HF}$ and $\mathrm{HNO}_{3}$ etched samples showed different morphologies since their oxygen content was higher than the $40 \% \mathrm{HF}$ and $50 \%$ HF etched samples. The 1 hour $\mathrm{HF}$ and $\mathrm{HNO}_{3}$ etched sample had mostly elongated grains, the 4 hour and 24 hour $\mathrm{HF}$ and $\mathrm{HNO}_{3}$ etched samples had small grains with visible porosity. 1 hour, 4 hour and 24 hour $\mathrm{HF}$ and $\mathrm{HNO}_{3}$ etched samples had a $6.68 \mu \mathrm{m}, 1.75 \mu \mathrm{m}$, and $1.57 \mu \mathrm{m}$ average grain size respectively. To be consistent, $1.5 \mathrm{wt} . \%$ carbon was added to all the samples' matrix. The 4-hour and 24-hour HF and $\mathrm{HNO}_{3}$ etched $\mathrm{SiC}$ powders had 5.07 wt.\% and 5.92 wt.\% 
oxygen content respectively. Since these two powders had a high oxygen content, the amount of additional carbon was not enough to remove residual oxygen; thus, the samples could not achieve high density.
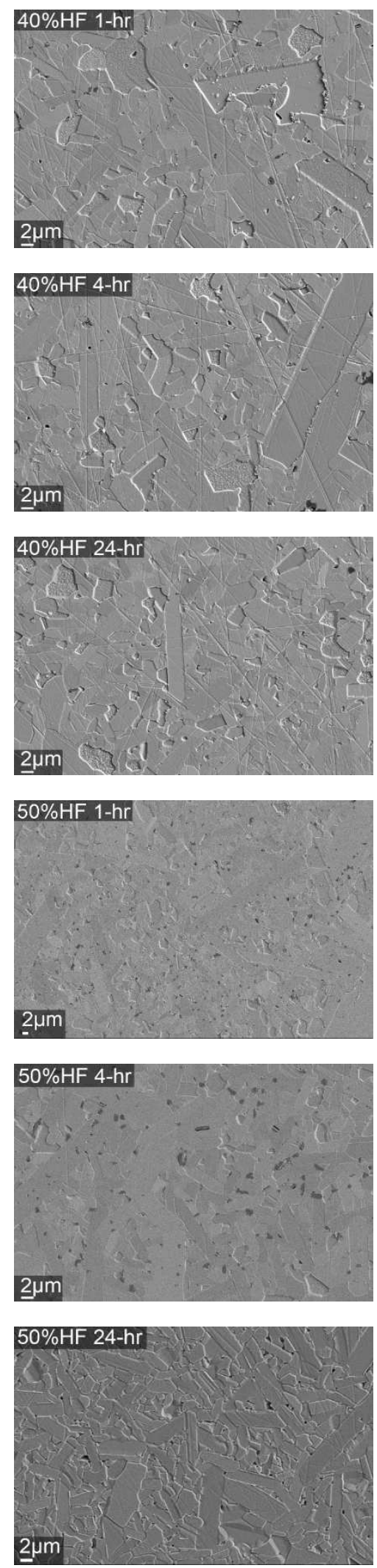
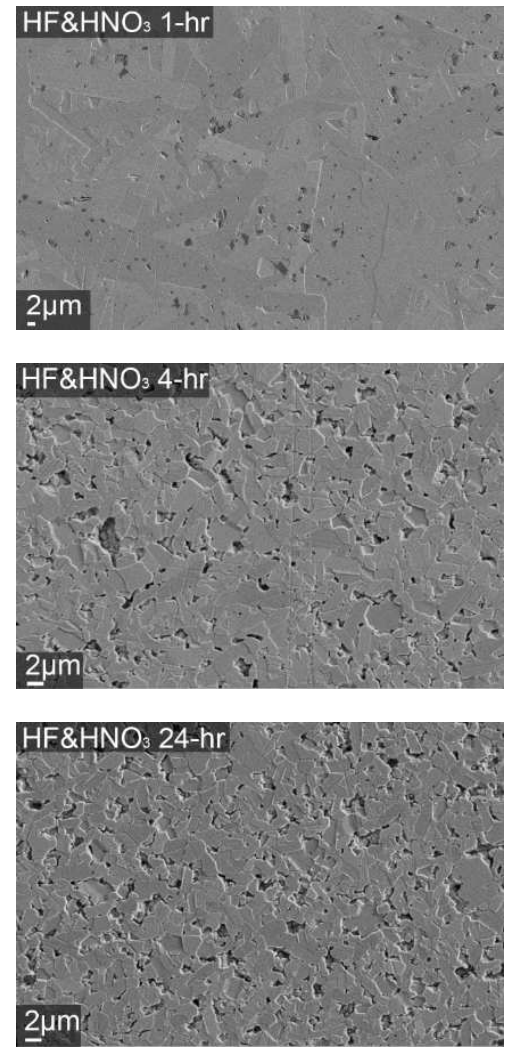

Figure 2. Microstructure images for different etched fine $\mathrm{SiC}$.

Density, grain size and elastic properties of dense fine silicon carbide results can be seen in Table 3. Each value represents the mean of five analyses. For $40 \% \mathrm{HF}$ etched samples' density values were $3.18 \mathrm{~g} / \mathrm{cm}^{3}(1,4,24$ hour), the Young's modulus was 416GPa (1 hour) and $417 \mathrm{GPa}(4,24$ hour). The shear modulus values were $177 \mathrm{GPa}(1,4,24$ hour). The bulk modulus were $215 \mathrm{GPa}$ (1, 4, 24 hour). The density and elastic properties were almost the same since their etched starting powder's oxygen content was similar. The 1-hour and the 4-hour 50\% HF etched samples' density values were $3.21 \mathrm{~g} / \mathrm{cm}^{3}$, and the 24-hour $50 \% \mathrm{HF}$ etched sample's density value was $3.20 \mathrm{~g} / \mathrm{cm}^{3}$. The samples have reached the theoretical density of silicon carbide. The Youngs modulus was $423 \mathrm{GPa}$ (1 hour), $424 \mathrm{GPa}$ (4 hour) and 417 GPa (24 hour). The shear modulus was $180 \mathrm{GPa}$ (1 hour), $180 \mathrm{GPa}$ (4 hour) and $177 \mathrm{GPa}$ (24 hour). The bulk modulus value was $219 \mathrm{GPa}$ (1 hour), $220 \mathrm{GPa}$ (4 hour) and $216 \mathrm{GPa}$ (24 hour). Due to the high oxygen content of the starting powders' of the $\mathrm{HF}$ and $\mathrm{HNO}_{3}$ etched samples', the samples could not reach high density. The density of the sample was $3.17 \mathrm{~g} / \mathrm{cm}^{3}$ (1 hour), $3.14 \mathrm{~g} / \mathrm{cm}^{3}$ (4 hour) and $3.09 \mathrm{~g} / \mathrm{cm}^{3}$ (24 hour). The Young's modulus was $418 \mathrm{GPa}$ (1 hour), $412 \mathrm{GPa}$ (4 hour) and $407 \mathrm{GPa}$ (24 hour). The shear modulus was 178 $\mathrm{GPa}$ (1 hour), $175 \mathrm{GPa}$ (4 hour) and $173 \mathrm{GPa}$ (24 hour), and the bulk modulus was $216 \mathrm{GPa}$ ( 1 hour), $213 \mathrm{GPa}$ (4 hour) and $208 \mathrm{GPa}$ (24 hour) when increasing the etching time. It is clear that having a high oxygen content has a negative effect on density and elastic properties of samples. Accordingly, the analysis results that increasing the oxygen content decreases the density, and consequently, the samples that have a lower 
density will have greater porosity as shown in literature [8]. Having porosity in samples reduces the elastic properties of samples. Wilhelm et al. also mention that oxygen content of silicon carbide was one of the variables to affect mechanical properties [28].

Table 3. Density, grain size and elastic properties of dense fine $\mathrm{SiC}$.

\begin{tabular}{|c|c|c|c|c|c|}
\hline Sample & Density $\left(\mathrm{g} / \mathrm{cm}^{3}\right)$ & Average Grain Size $(\mu \mathrm{m})($ Std. Dev) & E (GPa) & G (GPa) & K (GPa) \\
\hline $40 \% \mathrm{HF}-1-\mathrm{hr}$ & $3.180 \pm 0.002$ & $3.57 \pm 1.30$ & $416 \pm 8$ & $177 \pm 4$ & $215 \pm 4$ \\
\hline $40 \% \mathrm{HF}-4-\mathrm{hr}$ & $3.180 \pm 0.002$ & $3.02 \pm 0.61$ & $417 \pm 8$ & $177 \pm 4$ & $215 \pm 4$ \\
\hline $40 \% \mathrm{HF}-24-\mathrm{hr}$ & $3.180 \pm 0.001$ & $2.80 \pm 0.89$ & $417 \pm 8$ & $177 \pm 4$ & $215 \pm 4$ \\
\hline $50 \% \mathrm{HF}-1-\mathrm{hr}$ & $3.210 \pm 0.001$ & $2.89 \pm 0.99$ & $423 \pm 9$ & $180 \pm 4$ & $219 \pm 4$ \\
\hline $50 \% \mathrm{HF}-4-\mathrm{hr}$ & $3.210 \pm 0.001$ & $2.71 \pm 0.82$ & $424 \pm 9$ & $180 \pm 4$ & $220 \pm 4$ \\
\hline $50 \% \mathrm{HF}-24-\mathrm{hr}$ & $3.200 \pm 0.001$ & $2.63 \pm 0.79$ & $417 \pm 8$ & $177 \pm 4$ & $216 \pm 4$ \\
\hline $\mathrm{HF} \& \mathrm{HNO}_{3}-4-\mathrm{hr}$ & $3.140 \pm 0.002$ & $1.75 \pm 0.26$ & $412 \pm 8$ & $175 \pm 4$ & $213 \pm 4$ \\
\hline $\mathrm{HF} \& \mathrm{HNO}_{3}-24-\mathrm{hr}$ & $3.090 \pm 0.002$ & $1.57 \pm 0.44$ & $407 \pm 8$ & $173 \pm 4$ & $208 \pm 4$ \\
\hline
\end{tabular}

\section{Coarse SiC (Saint Gobain)}

Coarse SiC samples' microstructural images can be seen in Figure 3. It showed slight differences in grain size, however the grain morphology appeared to be similar between samples. All samples showed equiaxed grain shape, and with increasing the oxygen content, the average grain size of samples increased. Sample produced with freshly etched powder (day 0) had $1.68 \mu \mathrm{m}$ average grain size, while the higher oxygen content sample (day 9) had $3.34 \mu \mathrm{m}$ average grain size. It showed that the oxygen content of the starting powder affects the grain size of the materials. This result was also supported with the literature, when Vassen et. al. mentioned that oxygen content of silicon carbide caused grain growth and inhibited the densification [29].
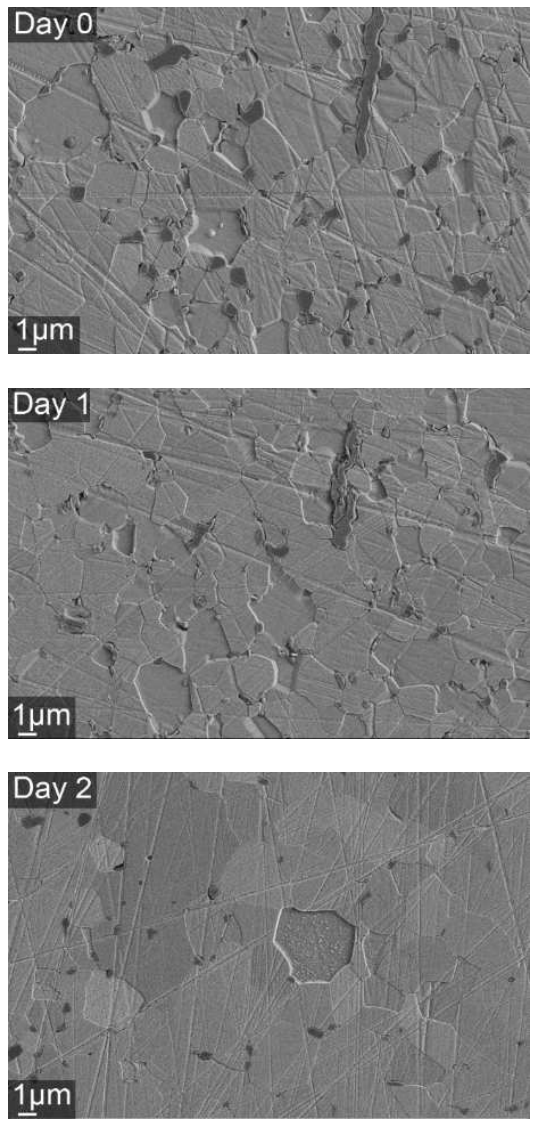
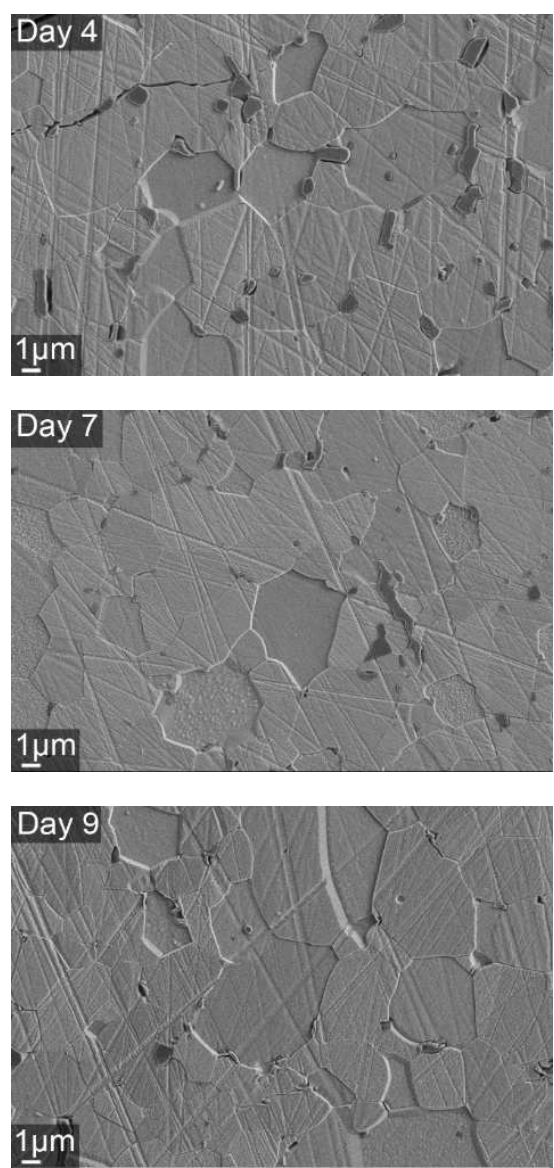

Figure 3. Microstructure images of aged coarse SiC for different days.

Density, grain size and elastic properties of dense coarse silicon carbide results can be seen in Table 4 . The density of the sample changed from $3.17 \mathrm{~g} / \mathrm{cm}^{3}$ to $3.14 \mathrm{~g} / \mathrm{cm}^{3}$, the Young's modulus decreased from $417 \mathrm{GPa}$ to $407 \mathrm{GPa}$, the shear modulus changed from $177 \mathrm{GPa}$ to $173 \mathrm{GPa}$, and the bulk modulus dropped from $217 \mathrm{GPa}$ to $210 \mathrm{GPa}$ while aging the powder. It was clear that increasing the oxygen content had a negative effect on the density and elastic properties of samples. Increasing the oxygen content decreased the density and elastic properties values. 
Table 4. Density, grain size and elastic properties of dense coarse SiC for different days.

\begin{tabular}{llllll}
\hline Sample & Density $\left(\mathbf{g} / \mathbf{c m}^{\mathbf{3}}\right)$ & Average Grain Size $(\boldsymbol{\mu m}) \mathbf{( S t d . ~ D e v )}$ & $\mathbf{E}(\mathbf{G P a})$ & $\mathbf{G}(\mathbf{G P a})$ & K $(\mathbf{G P a})$ \\
\hline Day 0 & $3.170 \pm 0.001$ & $1.68 \pm 0.46$ & $417 \pm 8$ & $177 \pm 4$ & $217 \pm 4$ \\
Day 1 & $3.160 \pm 0.002$ & $1.85 \pm 0.33$ & $415 \pm 8$ & $176 \pm 4$ & $215 \pm 4$ \\
Day 2 & $3.160 \pm 0.001$ & $2.69 \pm 0.41$ & $413 \pm 8$ & $175 \pm 4$ & $214 \pm 4$ \\
Day 4 & $3.160 \pm 0.002$ & $2.73 \pm 0.81$ & $412 \pm 8$ & $175 \pm 4$ & $213 \pm 4$ \\
Day 7 & $3.160 \pm 0.003$ & $3.07 \pm 1.16$ & $411 \pm 8$ & $174 \pm 4$ & $213 \pm 4$ \\
Day 9 & $3.140 \pm 0.002$ & $3.34 \pm 0.93$ & $407 \pm 8$ & $173 \pm 4$ & $210 \pm 4$ \\
\hline
\end{tabular}

\section{Conclusion}

In this research, a fine particle size $\mathrm{SiC}$ (H. C. Starck UF 25 Silicon Carbide), coarser particle size SiC (Saint Gobain Silicon Carbide) were densified using SPS with boron carbide and carbon additives. The oxygen content of the starting powders was modified by acid etching and adding carbon. It showed that when the concentration of hydrofluoric acid increased, the efficiency of acid etching also increased to remove the oxide layer. Moreover, with increasing the etching time, the oxygen content of the etched powder decreased. Since the 1 hour etching process was more effective in the time period, the silicon carbide powder etched for 1 hour with $50 \% \mathrm{HF}$ was selected.

SEM images of fine $\mathrm{SiC}$ (H. C. Stark silicon carbide) showed that they had mainly elongated grains. In addition to this, by increasing the etching time, the grain size decreased. It means that the high oxygen content of powders caused grain coarsening. Ultrasound analysis results showed that the high oxygen content also affected the elastic properties and density. Sample with the high oxygen content had a lower Young's modulus, shear modulus and bulk modulus, and they could not reach full density due to the oxide layer.

The coarse $\mathrm{SiC}$ (Saint Gobain) powder was etched only for 1 hour with $50 \% \mathrm{HF}$, and the powders were sintered at different times to see the effect of oxygen content of powder. SEM images of coarse silicon carbide showed that they had equiaxed grain shape, however the grain sizes changed by day. Sample made with freshly etched powder (day 0) had smaller grain sizes while higher oxygen content powder (day 9) showed bigger grain sizes. Sample made with the lowest oxygen content also had higher density and mechanical properties (Young's modulus, shear modulus, and bulk modulus) than higher oxygen content powders. It was clear that increasing the oxygen content decreased the density and elastic properties.

\section{Acknowledgements}

Research was sponsored by the National Science Foundation I/UCRC Award No. 1540027. The views and conclusions contained in this document are those of the authors and should not be interpreted as representing the official policies, either expressed or implied, of the National Science Foundation or the U.S. Government. The U.S. Government is authorized to reproduce and distribute reprints for Government purposes notwithstanding any copyright notation herein. Additional funding was provided by the Materials for Extreme Dynamic Environments program sponsored by the US Army Research Laboratory Cooperative Agreement (W911NF-12-2-0022). Zeynep Ayguzer Yasar acknowledges the graduate scholarship from the Ministry of National Education of the Republic of Turkey.

\section{References}

[1] K. Raju, D.-H. Yoon, Sintering additives for $\mathrm{SiC}$ based on the reactivity: a review, Ceram. Int. 42 (16) (2016) 17947-17962.

[2] D. Moskovskikh, Y. Song, S. Rouvimov, A. Rogachev, A. Mukasyan, Silicon carbide Ceramics: mechanical activation, Combustion and spark plasma sintering, Ceram. Int. 42 (11) (2016) 12686-12693.

[3] J. Zhang, D. Jiang, Q. Lin, Z. Chen, Z. Huang, Properties of silicon carbide ceramics from gelcasting and pressureless sintering, Mater. Des. (1980-2015) 65 (2015) 12-16.

[4] G. Magnani, A. Brentari, E. Burresi, G. Raiteri, Pressureless sintered silicon carbide with enhanced mechanical properties obtained by the two-step sintering method, Ceram. Int. 40 (1) (2014) 1759-1763.

[5] B. P. Groth, On the use of Raman spectroscopy and instrumented indentation for characterizing damage in machined carbide ceramics, Rutgers The State University of New Jersey-New Brunswick 2013.

[6] D. M. Slusark, The effect of microstructural variation on the mechanical and acoustic properties of silicon carbide, Rutgers The State University of New Jersey-New Brunswick 2012.

[7] K. K. Saxena, S. Agarwal, S. K. Khare, Surface characterization, material removal mechanism and material migration study of micro EDM process on conductive $\mathrm{SiC}$, Procedia CIRP, 42 (2016) 179-184.

[8] B. Lanfant, Y. Leconte, G. Bonnefont, V. Garnier, Y. Jorand, S. Le Gallet, M. Pinault, N. Herlin-Boime, F. Bernard, G. Fantozzi, Effects of carbon and oxygen on the spark plasma sintering additive-free densification and on the mechanical properties of nanostructured $\mathrm{SiC}$ ceramics, Journal of the European Ceramic Society, 35 (2015) 3369-3379.

[9] D. Ahmoye, Pressureless Sintering and Mechanical Properties of Silicon Carbon Composites with in-situ Converted Titanium Dioxide to Titanium Carbon, 2010.

[10] H. Liang, X. Yao, Z. Huang, Y. Zeng, B. Su, Effect of sintering techniques on the microstructure of liquid-phasesintered SiC ceramics, J. Eur. Ceram. Soc. 36 (8) (2016) 1863-1871. 
[11] P. Šajgalík, J. Sedláček, Z. Lenčéš, J. Dusza, H.-T. Lin, Additive-free hot-pressed silicon carbide ceramics-A material with exceptional mechanical properties, Journal of the European Ceramic Society, 36 (6) (2016) 1333-1341.

[12] J. Roy, S. Chandra, S. Das, S. Maitra, Oxidation behaviour of silicon carbide-a review, Rev. Adv. Mater. Sci, 38 (2014) 2939.

[13] J. Quanli, Z. Haijun, L. Suping, J. Xiaolin, Effect of particle size on oxidation of silicon carbide powders, Ceramics international, 33 (2007) 309-313.

[14] J. Evans, Pressureless Sintering of Boron Carbide, Imperial College London Department of Materials Science and Engineering, London, (2014).

[15] Z. Ayguzer Yasar, V. A. DeLucca, R. A. Haber, Influence of oxygen content on the microstructure and mechanical properties of SPS SiC, Ceramics international (2018) 2324823253

[16] S. Grasso, T. Saunders, H. Porwal, M. Reece, Ultra-high temperature spark plasma sintering of $\alpha-\mathrm{SiC}$, Ceramic international 41 (2015) 225-230.

[17] H. Tanaka, Silicon carbide powder and sintered materials, Journal of the Ceramic Society of Japan, 119 (2011) 218-233.

[18] M. Balog, K. Sedlackova, P. Zifcak, and J. Janega, Liquid phase sintering of $\mathrm{SiC}$ with rare-earth oxides, CeramicsSilikaty, 49 (2005) 259-262.

[19] L. Stobierski and A. Gubernat, Sintering of silicon carbide I. Effect of carbon, Ceramics international, 29 (2003) 287-292. 145

[20] W. J. Clegg, Role of Carbon in the Sintering of Boron Doped Silicon Carbide, Journal of the American Ceramic Society, 83 (2000) 1039-1043.
[21] W. v. Rijswijk and D. J. Shanefield, Effects of carbon as a sintering aid in silicon carbide, Journal of the American Ceramic Society, 73 (1990) 148-149.

[22] R. Hamminger, Carbon inclusions in sintered silicon carbide, Journal of the American Ceramic Society, 72 (1989) 17411744.

[23] M. Rączka, G. Górny, L. Stobierski, and K. Rożniatowski, Effect of carbon content on the microstructure and properties of silicon carbide-based sinters, Materials characterization, 46 (2001) 245-249.

[24] G. Magnani, G. Sico, A. Brentari, P. Fabbri, Solid-state pressureless sintering of silicon carbide below $2000^{\circ} \mathrm{C}$, Journal of the European Ceramic Society, 3 (2014) 4095-4098.

[25] Z. Munir, U. Anselmi-Tamburini, and M. Ohyanagi, The effect of electric field and pressure on the synthesis and consolidation of materials: a review of the spark plasma sintering method, Journal of Materials Science, 41 (2006) 763-777.

[26] F. Guillard, A. Allemand, J.-D. Lulewicz, and J. Galy, Densification of $\mathrm{SiC}$ by SPS-effects of time, temperature and pressure, Journal of the European ceramic Society, 27 (2007) $2725-2728$.

[27] S. Hayun, V. Paris, R. Mitrani, S. Kalabukhov, M. P. Dariel, E. Zaretsky, N. Frage, Microstructure and mechanical properties of silicon carbide processed by spark plasma sintering (SPS) Ceramics international, 38 (2012) 6335-6340.

[28] M. Wilhelm, M. Kornfeld, W. Wruss, Development of SiC-Si composites with fine-grained $\mathrm{SiC}$ microstructures, Journal of the European Ceramic Society, 19 (1999) 2155-2163.

[29] R. Vassen, D. Stöver, Processing and properties of nanograin silicon carbide, Journal of the American Ceramic Society, 82 (1999) 2585-2593. 